\title{
TALKING THE IS INNOVATION WALK
}

\author{
E. Burton Swanson \\ Anderson School \\ University of California, Los Angeles \\ Los Angeles, California \\ U.S.A.
}

\section{INTRODUCTION}

Talk matters where information technology is concerned; it has consequences. In this conference we as participants take seriously the discourse surrounding IT and its applications. We examine the assumptions embedded in this discourse so as to discern underlying worldviews. We consider discourse both local, as within organizations, and global, as among firms around the world. We thereby probe how our work in researching and applying IT is shaped. Discourse is apparently serious business, especially when it is formal and orderly, as among academics. ${ }^{1}$

What about when IT talk is informal and rather disorderly, as when buzzwords are bandied about in everyday practice? In recent years, I have taken a special interest in certain of our field's prominent buzzwords. I have become especially intrigued with their role in innovating with IT among organizations. In this context, I argue, buzzwords matter too, perhaps more than we might imagine.

Buzzwords-ERP! E-commerce! CRM! They all flit about. How do managers make sense of the buzz that surrounds them? With considerable difficulty, Ramiller's (2001) research finds, as shown in Illustration 1. Here we see that, although some innovations present themselves as "silver bullets," managers are often disappointed in this regard. Also, where the buzz associated with an innovation is particularly intense, managers may feel pressured to join the apparent bandwagon. Whatever the rationale presented for the innovation, managers may have difficulty ascertaining the innovation's likely return-oninvestment. They may or may not perceive that the innovation represents an old

${ }^{1}$ Well, OK, the banquet history of WG8.2 conferences offers a notorious exception. 


\section{Illustration 1. Making Sense of the Buzz}

(from Ramiller 2001)

“... and I keep waiting for a silver bullet, a magic formula, an answer to all my prayers, and it never happens!” (IS Manager)

"...they jumped into it, because it was the latest and the greatest craze at the time and they figured they had to sign up for it, too .... and, 'We've got to go in and we've got to do what everybody else is doing." (Consultant)

"In today's business world you really have to grab right at the money. Profit before taxes, cash, cost reduction. We're gonna take a building and close it, because of this technology. We're gonna reduce our administrative staff. I mean, hard core numbers." (IS Manager)

"I think [data warehouse] is a well-worn concept, and I think a whole lot a people thought it was a good idea 30 years ago. So, yeah ...it's a 30 -yearold concept with a different name. It's sort of a rose by any other name." (IS Manager)

“... you see if it has meaning, you know, as you understand it. Would it help your organization, would it help certain areas of your organization, where might it help, what are the benefits of it? ...you really need to drill down, in terms of what these concepts are, and what it means from an implementer's point of view, and what it can mean to your business." (IS Manager)

idea dressed up in new, more fashionable words. They may further be challenged to translate the broad promise of the innovation into particulars compelling to their own enterprises.

Notwithstanding such difficulties, managers ultimately face innovation adoption and implementation decisions. They must choose whether and how to walk the IS innovation talk. Or, they may ignore it, perhaps at their organizations' peril. In this paper, we ask how managers' decisions are shaped by the broader discourse surrounding the innovation itself. I consider IS innovation within the broader interorganizational field (DiMaggio and Powell 1983), in an institutional context (Scott 1995), where discourse lies at the heart of the innovation's diffusion, and where organizations learn from each other (Attewell 
1992; Robey et al. 2000). It is in this broader field that the community talks the IS innovation walk. ${ }^{2}$

\section{INNOVATION AS AN ORGANIZATIONAL PROCESS}

We first revisit some basics of innovation theory (Rogers 1995). We remind ourselves that an innovation is defined as an idea, practice, or object new to the organization adopting it. ${ }^{3}$ In our context, the application of IT, the innovation is often identified by a buzzword. Familiar examples include ERP (enterprise resource planning), CRM (customer relationship management), and data warehouse.

Innovation diffusion refers to the gradual spread of the innovation among organizations. It implies communication leading to adoption and implementation decisions. Interestingly, when we reflect upon it, innovation typically involves more imitation than it does invention. Any organization adopts relatively early or late compared to others. And where the diffusion pattern follows the familiar S-shaped curve, the majority of firms follow the lead of a few innovators and early adopters.

More specifically, then, how do organizations engage the innovations they face? To answer this question, it will be helpful to examine innovation more closely as an organizational process. In Illustration 2 we sketch our own interpretation, which parallels Rogers' familiar stage model. ${ }^{4}$ Four subprocesses - termed comprehension, adoption, implementation, and assimilation-

${ }^{2}$ I borrow from Weick's (1995) use of the expression. "To 'talk the walk' is to be opportunistic in the best sense of the word. It is to search for words that make sense of current walking that is adaptive for reasons that are not yet clear" (p. 183). As I shall argue, making sense of an IS innovation is essentially what propels its diffusion.

${ }^{3}$ I take an organizational view in this paper. Individual innovation is not considered, except where the individual acts on the organization's behalf.

${ }^{4}$ Rogers (1995) describes the innovation-decision process "through which an individual (or other decision-making unit) passes from (1) first knowledge of an innovation, (2) to forming an attitude toward the innovation, (3) to a decision to adopt or reject, (4) to implementation of the new idea, and (5) to confirmation of this decision" (p. 161). He also describes the organization's innovation process as consisting of two broad activities, initiation (leading to decision) and implementation, which includes "routinizing" as the last step (p. 392). See also Wolfe's (1994) review of alternative stage models. 


\section{Illustration 2. The Organization's Innovation Process}

\section{Comprehension}

understanding the innovation in terms of the community's organizing vision for it

\section{Adoption}

deciding whether and when to undertake the innovation, making a resource commitment

undertaking the project, making it happen, bringing the innovation to life for its users

\section{Implementation}

making the innovation a part of routine, everyday

\section{Assimilation}

are understood here to comprise innovation as a whole. These subprocesses unfold roughly in the order they are presented. ${ }^{5}$

Briefly, comprehension consists of learning about the innovation in terms of the community's "organizing vision" for it (discussed in the next section). As we have already noted, making organizational sense of the innovation is often problematic. But, significantly, no firm finds itself alone in this situation. Indeed, the broader community is characteristically mobilized to provide help and bring the single organization into the collective innovative fold. We will have more to say about this momentarily.

The organization engages adoption when it shifts its attention toward deciding whether and when it should itself undertake the innovation. The broader community's rationale for the innovation is now typically translated into a local justification. Should the "business case" be persuasive, the innovation is adopted and resources are committed to its implementation. ${ }^{6}$

Implementation is typically undertaken in the form of a planned and staffed project. Schedule, budget, and deliverables become dominant concerns. "Build or buy" decisions must be made. The goal is to successfully assemble, deploy,

${ }^{5}$ The overlaps among subprocesses shown in the sketch are arbitrarily drawn. They illustrate rather than define possible concurrencies.

${ }^{6}$ I refer here to primary adoption by the firm, as distinguished from secondary adoption by individuals (Gallivan 2001). The extent to which the firm adopts through a rational or pseudo-rational process is left an open question in our framework. 
and bring a system to life for its intended users (Swanson 1988). Testing, training, and change management may all be important in making the transition.

Finally, assimilation is the process by which the deployed innovation becomes a part of routine, everyday practice. ${ }^{7}$ Now, the innovation is taken up and appropriated by its users (DeSanctis and Poole 1994), gradually becoming imbedded in work practices. With continued learning, it becomes infused in the enterprise. $^{8}$

Of course, the innovation process can also go wrong anywhere along the way. The innovation may not be well understood. The adoption decision may be based on bad assumptions. The implementation approach may be misguided. Users may not accept the technology thrust upon them. The research of the IFIP Working Group 8.2 addressing the interaction of IS and organizations has for many years focused on such problems and sought to understand them. However, the comprehension of IS innovations across firms has not been much studied. More broadly, an institutional perspective on information systems has been largely lacking (Orlikowski and Barley 2001). ${ }^{9}$ Where innovation is concerned, this is especially problematic. I believe there is much here to be learned.

\section{THE ORGANIZING VISION CONJECTURE}

As already noted, where the application of IT is involved, the organization's comprehension of the innovation can be problematic. The basic concept of the innovation may not be easy to grasp. While the new IT may present itself as an attractive package, the ramifications for organizational change may not be at all apparent. The potential benefits to be gained may be only vaguely articulated. Hence the organization may need to invest significant resources toward understanding the innovation. However, as already mentioned, the single organization is not alone in this regard.

Recently we have suggested that the broader community responds to this collective need by articulating an organizing vision for the innovation. We define an organizing vision simply as a focal community idea for applying IT in organizations (Swanson and Ramiller 1997). It comprises a basic notion of what

${ }^{7}$ We note that Fichman and Kemerer (1999) extend the notion of assimilation to incorporate the entirety of the innovation process as we have sketched it. Fichman (2000) provides a thorough review of recent literature.

${ }^{8}$ Infusion of an innovation in an organization involves both depth and breadth of functional penetration (Cooper and Zmud 1990; Saga and Zmud 1994).

${ }^{9}$ The work of Kling and his colleagues over many years is a notable exception. See, for example, Kling and Iaconno (1984). 
the innovation is and what it is good for. It makes some sense of the innovation (Weick 1995). It thus serves the innovation's interpretation and legitimation, and further, the mobilization of entrepreneurial and market forces. As suggested above, it is also characteristically identified by a buzzword, such as ERP or CRM, which attracts attention to it.

As an idea to be communicated, the organizing vision is essentially a linguistic construction, produced and sustained through community discourse, the parties to which are united by a common interest in shaping it (Swanson and Ramiller 1997). This discourse occurs in many public venues, through the trade press, conventions, user group meetings, educational forums, electronic discussion groups, and the like. It has further threads in numerous private communications among individuals.

A fundamental conjecture is that the organizing vision drives and is driven by the innovation's adoption and diffusion. It is in this sense that talk matters in the diffusion of IS innovations, as suggested earlier. The innovation spreads not through mere communicative "contact," as with the spread of diseases, but according to the substance and sources of the message, informed by the vision. The organizing vision thus needs to be understood in terms of its linguistic construction and particulars, in addition to its means and paths of conveyance.

Finally, the organizing vision is seen as having a characteristic career in terms of its visibility, prominence, and influence over time. The vision comes into being, "launched" by certain interested proponents. A buzzword is attached to it. With good fortune, the vision gains acceptance, even as it is worked over and reshaped, often pushed and pulled in different directions. It may for a while even achieve high fashionableness (Wang 2002). Eventually, however, according to the progress and success of the innovation's diffusion, and the community's interpretation of it, the vision may fade or fall into disrepair.

The career of ERP over the 1990s illustrates. The ERP vision was articulated first by the Gartner Group in 1990; an early report specifies the requisite technical environment (such as client server architecture and graphical user interface) and functionality (such as integrative features). According to the author: "Recent events in hardware, operating systems, and applications are crystalizing [sic] our definition of Enterprise Resource Planning systems-the Next-Generation MRP II"'(Wylie 1990). ${ }^{10}$ Thus launched, ERP gradually gained acceptance and reached its greatest popularity in the mid- to late-1990s, after which enthusiasm for it began to wane, as portrayed in Illustration 3.

Playfully, we suggest that an organizing vision can be likened to a hot-air balloon, given lift by the talk that shapes it. When discourse waxes, the vision

${ }^{10} \mathrm{ERP}$ thus grew from industry-specific roots in manufacturing. Klaus et al. (2000) review the ERP concept and its history. 


\section{Illustration 3. ERP's Career}

“Here comes SAP!" (Lieber 1995)

What's all the buzz about? Simply put, $R / 3$ seems to be a case of the right product at the right time." (Xenakis 1996)

"The growing number of horror stories about failed or out-of-control projects should certainly give managers pause." (Davenport 1998)

"[I] t becomes clear the enterprise resource planning strategies were really designed to get the corporate house in order." (Connolly 1999)

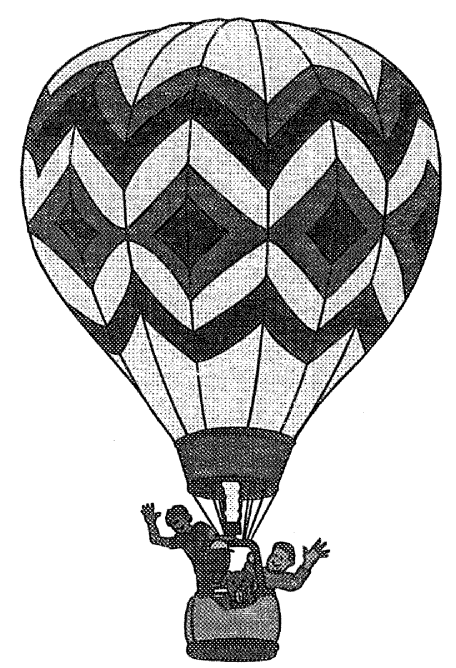

"As 1999 winds down, it seems ironic that enterprise resource planning (ERP) has again attained almost the same dubious status it had when the acronym entered the lexicon in 1990 - that of an idea that would never work." (Keller 1999)

rises for more to see; when it wanes, the vision settles earthward. In other words: out of mind, out of sight.

The career of the organizing vision may be viewed as roughly paralleling the innovation's adoption and diffusion, while not necessarily tracing the same path. As we shall see, because this career is separately considered, it may be studied in its own right. We may thereby learn more about it, and most importantly, we can explore our fundamental conjecture. Is the discourse important to the innovation's adoption and diffusion, as we believe, or is it mostly just so much froth?

\section{TALKING THE INNOVATION WALK}

In this section, we explore aspects of the organizing vision conjecture. We consider several studies that speak to how organizing visions (as talk) shape the 
organization's innovation process (as walk). We focus on the shaping of innovation comprehension and adoption, in particular. We also comment on the shaping of implementation and assimilation.

\subsection{Shaping Comprehension}

How do organizations and their managers make sense of the new in IT? Ramiller's 1996 study combined field interviews with a survey of executives to probe the dimensions of reception of three organizing visions: electronic commerce, client server, and CASE (computer assisted software engineering) ${ }^{11}$ Factor analysis of survey item responses suggests that four dimensionsinterpretability, plausibility, importance, and discontinuity-account for substantial variance in reception. Interpretability reflects how intelligible and informative the executive finds the organizing vision. Plausibility refers to whether the vision is free of misunderstandings, exaggerations, and misplaced claims. Importance refers to the business benefits, practical acceptance, and community interest the executive associates with the vision. Discontinuity reflects the extent of the conceptual departure and implementation challenges posed.

As reflected by their discourse histories, the three visions were, when studied, in different stages of their careers. Electronic commerce was in early ascent; client server was in late ascent; and CASE was in descent. Managerial reception of the three visions in 1996 differed significantly across the four dimensions. Electronic commerce was viewed as most important, while CASE was seen as the least important even though it was also judged the most interpretable. Client server and CASE were both seen to be less plausible than electronic commerce. Client server was further perceived to pose the greatest discontinuity. Correlations between the (non-orthogonal) dimensions were consistent across the visions with one exception; interpretability and importance were positively associated for electronic commerce and client server, but negatively associated for CASE.

We are reminded that at any one time organizing visions compete with each other for managers' attention, a scarce resource (Simon 1971). The importance that managers attach to a vision is likely correlated with the attention they will give to it. At the time of Ramiller's mid-1990s study, the vision for electronic commerce was immature, but managers were already persuaded of its impor-

${ }^{11}$ See Ramiller and Swanson (2002). An illustrative survey item response is: "The company that waits to do $\mathrm{X}$ is going to fall dangerously behind" (agree-disagree). 
tance. They would give substantial attention to comprehending the vision's elaboration and development in the months to come.

Of course, before an organizing vision can compete for a manager's attention, the manager must become aware of it. Here we suggest that the buzzword associated with the innovation may be crucial to bringing the idea to the manager's first notice. "Have you heard of ERP?" becomes a pointed question to which managers can easily respond, whether or not they know anything at all about the innovation (or for that matter what the letters of the label stand for). We suspect that simple awareness of the buzzword is for many managers their first contact with the innovation and its organizing vision. Absent the buzzword, the vision lacks a vehicle for participative construction and communication. Beyond facilitating simple awareness, the buzzword serves as a linguistic portal into the community's broader discourse.

\subsection{Shaping Adoption}

How do organizing visions shape innovation adoptions? For present purposes, we frame an answer with the "adopter's dilemma" shown in Illustration 4. We portray this dilemma as the choice to adopt early, adopt with the majority, or adopt late (if at all). We propose that each alternative is problematic (and hence risky) in terms of its adoption know-why and implementation know-how. Specifically, the prospective early adopter might perceive competitive advantage anchored in its own know-why; however, the requisite know-how for the innovation is likely just emergent. At the other extreme, the prospective late adopter might benefit both from plentiful know-how and clarity in know-why; however, the risk might be in competitive survival. Why not then seek the safety of adopting with the majority? Here, we suggest that risks remain significant, although less obvious. The prospective adopter seeking competitive parity likely faces both a muddled know-why, because the majority's reasons for adoption will be diverse even while they are imitative, and a scarce know-how, because the majority must compete for know-how not yet scaled to meet the demand.

We argue that how the prospective adopter responds to this dilemma is likely to be shaped broadly by the community's organizing vision, not just by the firm's reasoning about its own situation and specifics. Adopters of IS innovations must typically anchor their rationales in local circumstances. However, often with the aid of consultants, they inevitably borrow substantially from the community's discourse and vision. While know-why and know-how will vary among adopters, they will have common elements.

With these ideas in mind, Swanson (2000) surveyed the know-why and know-how associated with organizations' adoption of ERP in the middle to late 1990s. It was during this period that ERP revenue achieved its greatest growth, 
Illustration 4. The Adopter's Dilemma

\begin{tabular}{|c|c|c|c|}
\hline Adopt early & $\begin{array}{l}\text { Competitive } \\
\text { advantage }\end{array}$ & $\begin{array}{l}\text { Know-why } \\
\text { specific to firm }\end{array}$ & $\begin{array}{l}\text { Know-how } \\
\text { emergent }\end{array}$ \\
\hline $\begin{array}{l}\text { Adopt with the } \\
\text { majority }\end{array}$ & $\begin{array}{l}\text { Competitive } \\
\text { Party }\end{array}$ & $\begin{array}{l}\text { Know-why } \\
\text { likely muddled }\end{array}$ & $\begin{array}{l}\text { Know-how } \\
\text { likely scarce }\end{array}$ \\
\hline $\begin{array}{l}\text { Adopt late (if } \\
\text { at all) }\end{array}$ & $\begin{array}{l}\text { Competitive } \\
\text { survival }\end{array}$ & $\begin{array}{l}\text { Know-why } \\
\text { likely clear }\end{array}$ & $\begin{array}{l}\text { Know-how } \\
\text { likely plentiful }\end{array}$ \\
\hline
\end{tabular}

while ERP discourse achieved high visibility (Wang 2002). Those that responded to our 1998-2000 survey, some 121 firms, had for the most part chosen to adopt ERP with the majority. We asked them to assess their adoption and implementation experience to date. Individual assessment items addressed the know-why of adoption, the know-how of implementation, and overall success. They were drawn from our own reading of the practitioner literature and taken to reflect the ERP organizing vision. Our conjecture was that reported ERP success would vary according to both know-why and know-how. In the middle to late 1990s, some reasons for adopting, as well as some abilities for implementing ERP would be better than others. Indeed, our findings seemed to confirm this. Those firms that adopted ERP for its business benefits, such as working more closely with suppliers and customers, reported greater success, as did those firms whose top management understood the implementation costs and provided the necessary resources (Swanson 2000).

Adopting an innovation with the majority may be particularly risky where the organizing vision has become highly fashionable. A management fashion is defined as "relatively transitory collective beliefs, disseminated by the discourse of management-knowledge entrepreneurs, that a management technique is at the forefront of rational management progress" (Abrahamson and Fairchild 1999, p. 709). The fashionable organizing vision tends to be over-inflated in terms of expectations for the innovation, further muddling adoption know-why. As the vision ascends in popularity, it is prone toward hype. It is noteworthy that the Gartner Group has originated a hype cycle concept to guide potential adopters in this regard. Illustration 5 describes Gartner's 2001 hype cycle for CRM. ${ }^{12}$

${ }^{12}$ The CRM hype cycle positions a bundle of CRM innovations along the curve. The overall concept is shown to have just fallen from the peak of inflated expectations, headed now for the trough of disillusionment. Note that Gartner suggests that being 


\section{Illustration 5. Illustrative Gartner Hype Cycle CRM 2001} (from Nelson 2001)

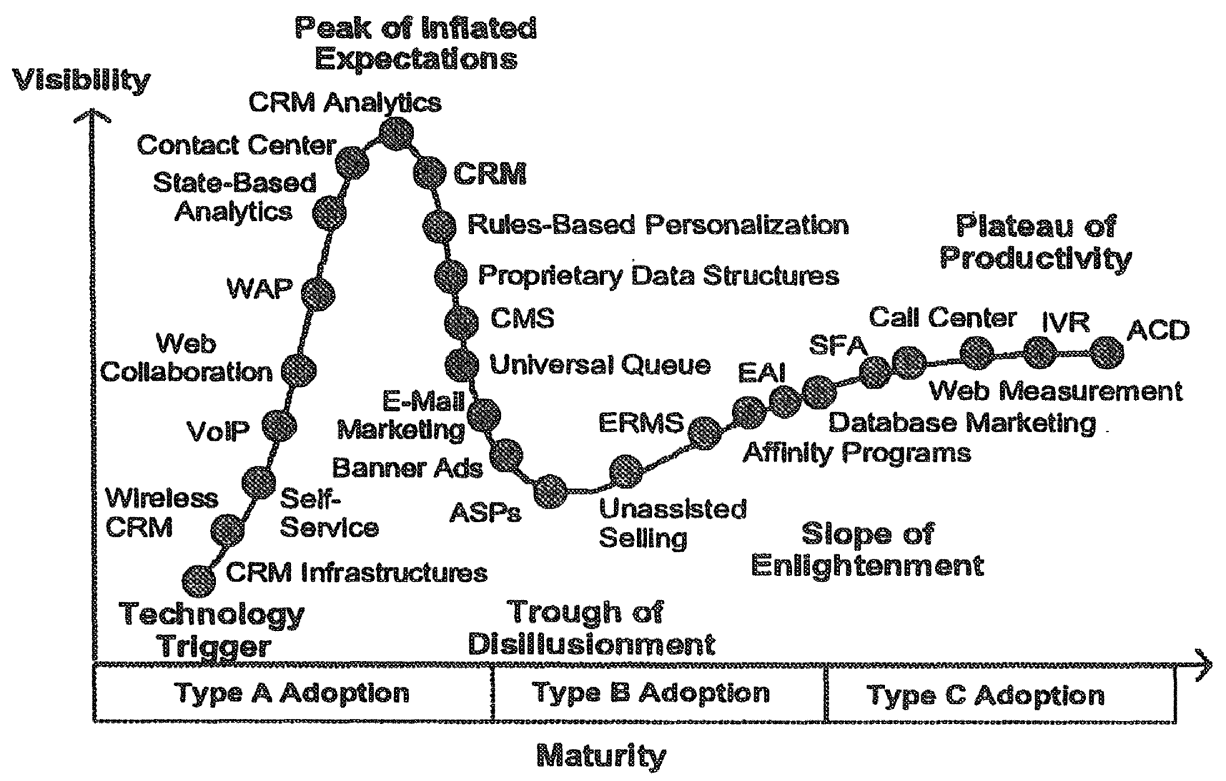

Note that the notion of inflated expectations suggests quite clearly that the community's know-why can pose risks to would-be adopters caught in the middle.

The research agenda of management fashion theorists is close to our own interests. Thus, one of its research questions is: does the lifecycle of discourse promoting a fashionable management technique coevolve with the lifecycle of the innovation's diffusion across organizations (Abrahamson and Fairchild 1999)? A second research question is: does the downswing in one management fashion in a management fashion niche coincide with the upswing of the next fashion in the niche? Wang (2002) explores the answers to these questions for ERP, examining the volume of published literature on the subject over time. Illustration 6, provided by Wang, shows that the upswing of ERP coincides with the downswing of its predecessors, MRP and MRP II, as would be expected. ${ }^{13}$

overly disillusioned with an innovation is itself a temporary phenomenon. Firth (2001) describes the CRM organizing vision.

${ }^{13} \mathrm{ERP}$ was in fact conceived to displace MRP II in its fashion niche (Wylie 1990). Every fashion niche is understood to have a finite carrying capacity, and the collapse of an old fashion often triggers the rise of a new one (Abrahamson and Fairchild 1999; Wang 2002). 


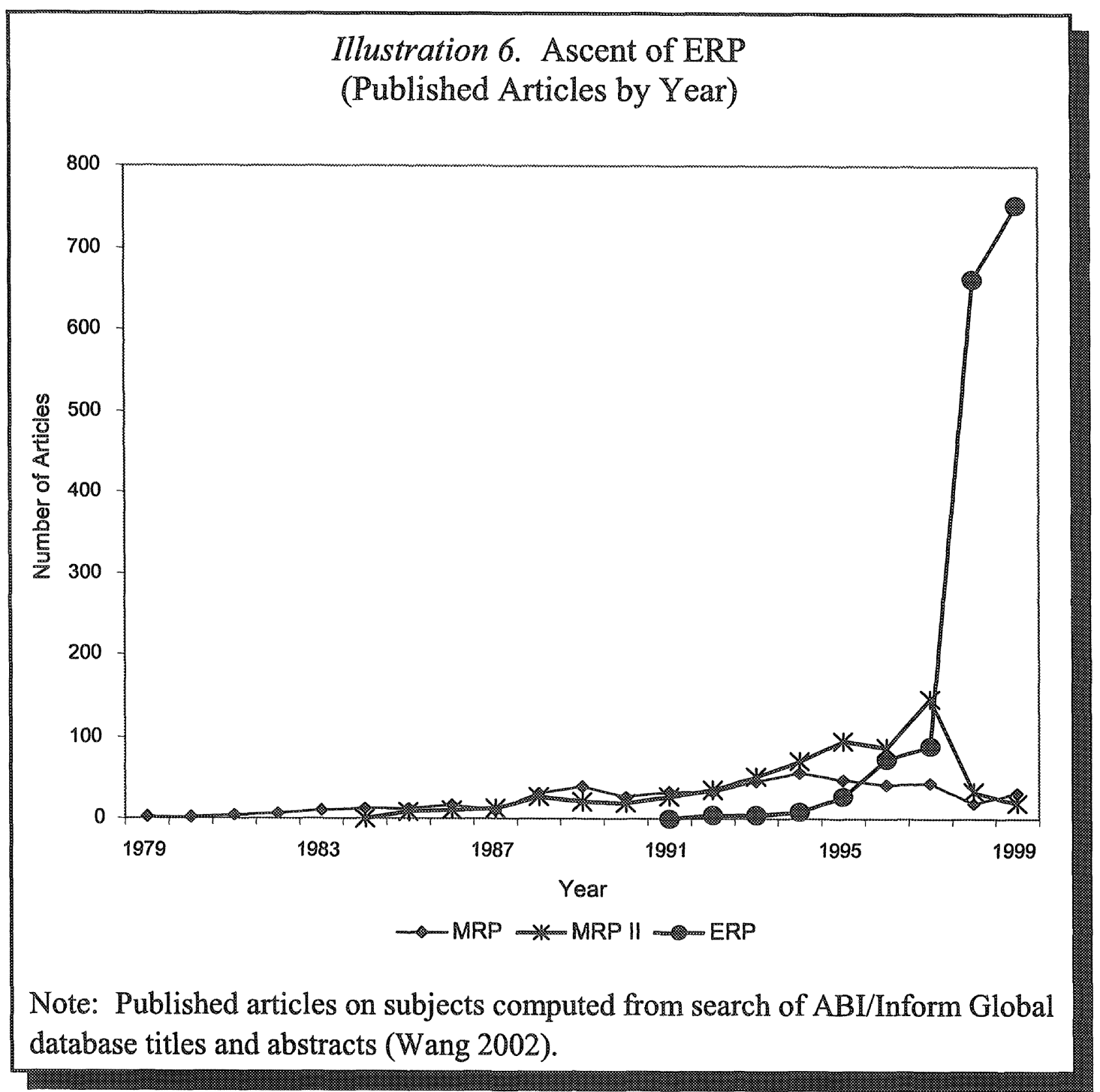

\subsection{Shaping Implementation}

How does an organizing vision shape a firm's implementation of its adopted innovation? As suggested above, the organizing vision may incorporate implementation wisdom pertaining to requisite know-how. Especially where implementation can be highly problematic, as with ERP, organizing to accomplish the innovation is likely to be a preoccupation. ${ }^{14}$ Additionally, consultancies com

${ }^{14}$ Among ERP implementation issues, for instance, is the division of responsibilities internally, and externally, with suppliers and third parties. The CIO's role here has been problematic. Willcocks and Sykes (2000) describe how many CIOs have been "asleep at the wheel" in the implementation of ERP. CIOS have failed to see that ERP is more 
peting for implementation contracts may have much to gain by making their competencies known in this regard. Hence, once the majority has made its move to adopt, much of the discourse surrounding an innovation may be implementation discourse, in some cases reshaping the vision itself. ${ }^{15}$ In the case of ERP, this is illustrated by the "plain vanilla" configuration, seen by many to be a wise choice given the complexities that might otherwise undermine implementation efforts (Smith 1999).

Pozzebon (2001) discusses the rhetorical closure (Pinch and Bijker 1984) of the ERP discourse, by which the notion that an ERP package might be custom-fit to the enterprise is foreclosed in favor of the idea that the enterprise must change its business processes to accommodate off-the-rack functionality. We note that such closure is likely to be characteristic of organizing visions informed by the community's early implementation experience. Indeed, it is intended to guide the choices of those who follow. Thus, Swanson (2000) finds that firms that willingly modified their business processes to take advantage of ERP package functionality report greater implementation success.

\subsection{Shaping Assimilation}

How, if at all, does an organizing vision affect a firm's assimilation of the innovation? Here, we consider first that the vision may shape initial expectations for the innovation among prospective users. Prior to actual use, the firm's comprehension of the vision, adapted to its own circumstances through the adoption decision, and further communicated through training as part of implementation, will no doubt affect user attitudes. Thus, assimilation will be preconditioned through earlier stages of the innovation process.

With implementation and first use, the innovational situation is likely to change profoundly, as problems bubble up everywhere. Work practices are rarely changed easily and without surprises. In the case of ERP, the firm's performance is often at first adversely affected (Markus and Tannis 2000; Ross, 1998). Business processes may take months to be restabilized. During this "shake-down" period, the vision may be called upon to help everyone "keep the faith" that better days are ahead.

than a software system; they have allowed suppliers and consultants to drive the process; they have tolerated outdated relationships and capabilities.

${ }^{15}$ See especially Davenport's (1998) discussion of ERP implementation problems, and his suggestions for giving more emphasis to enterprise aspects, for example, via a "federalist operating model" for addressing issues of required commonalities across regions and divisions. 
Still, eventually, if the innovation is to be assimilated, the local perception of the organizing vision must likely dissipate within the firm. It must give way to struggling with everyday work realities. In the end, whether the vision was even implemented may be called into question. In the case of ERP, for example, many firms seem to have implemented only a subset of the full suite of modules (Brown and Vessey 1999). Moreover, many may not have exploited the coordinative functionality promoted by the vision. In practice, an organization vision often comes up short of its promise.

For the innovation to be assimilated, users must in time appropriate it to their own ends, as mentioned above. Gradually, in also finding new uses for it, users make the innovation their own. They absorb it in their everyday work practices, adapting organizational structures and processes as may be needed. ${ }^{16}$ The innovation-in-practice may thus depart substantially from the original vision (Orlikowski 2000). Whatever its initial role in shaping expectations, the guiding vision within the firm becomes irrelevant and forgotten.

Or does it after all? Some organizing visions may persist well past their heydays, especially in the broader interorganizational field, through professional associations, user groups, and the like, which remain committed to advancement of their specialized practice. For these stakeholders in their hard-won institutional niche, if not for others, little may ever be taken for granted. They are now the defenders of what they understand to have been accomplished. And they are further the remaining promoters of the vision's still unfinished business.

\section{CONCLUSION}

To summarize, we have briefly explored how the discourse associated with an organizing vision is likely to drive adoption and diffusion of an IS innovation. We have focused on the individual firm's innovation process and its comprehension, adoption, implementation, and assimilation components. We suggest that comprehension is likely to be triggered by awareness of the buzzword, with attention subsequently given according to the vision's received importance. Adoption by the majority is likely to be driven in part by the vision's fashionableness, with the associated know-why muddled and the knowhow scarce, posing significant under-recognized risks. Implementation is likely to be guided by the popular know-how wisdom that also comes to be part of the

${ }^{16}$ In the case of ERP, roles and relationships are likely to change after implementation. The "power user" emerges as a central figure in organizational learning (Baskerville et al. 2000). Users are further likely to assume increased responsibility for in-house maintenance of the system, traditionally the role of the internal IS group (Hirt and Swanson, 2001). 
vision. Assimilation may be preconditioned largely through user expectations colored by the vision; however, the vision is likely to dissipate with assimilation.

Future research is of course needed to more closely examine these ideas. Additionally, research is needed to shed more light on the organizing vision's career. Here the analysis must focus on the broader interorganizational field, where the discourse is constructed. It is here that the community talks the IS innovation walk, such that the walk is further directed. Three broad questions are these. First, what enables an organizing vision to be successfully launched? Second, what makes an organizing vision fashionable? Third, what causes the organizing vision to fade away? To address questions such as these, an historically oriented study approach is likely to be the most useful.

\section{ACKNOWLEDGEMENTS}

I'm grateful to David Firth, Sandrine Poissonnet, Neil Ramiller, Ping Wang, and Yutaka Yamauchi for their comments on a draft of this paper.

\section{REFERENCES}

Abrahamson, E., and Fairchild, E. "Management Fashion: Lifecycles, Triggers, and Collective Learning Processes," Administrative Science Quarterly (44), 1999, pp. 708-740.

Attewell, P. "Technology Diffusion and Organizational Learning: the Case of Business Computing," Organization Science (3:1), 1992, pp. 1-19.

Baskerville, R., Pawlowski, S., and McLean, E. "Enterprise Resource Planning: Patterns of Convergence and Divergence," in W. J. Orlikowski, S. Ang, P. Weill, and J. I. DeGross (eds.), Proceedings of the $21^{\text {st }}$ International Conference on Information Systems, Brisbane, 2000, pp. 396-406.

Brown, C., and Vessey, I. "ERP Implementation Approaches: Toward a Contingency Framework," in P. De and J. I. DeGross (eds.), Proceedings of the $20^{\text {th }}$ International Conference on Information Systems, Charlotte, NC, 1999, pp. 411-416.

Connolly, J. "ERP: Corporate Cleanup," Computerworld (33:9), 1999, pp. 74-78.

Cooper, R. B., and Zmud, R. W. "Information Technology Implementation Research: A Technological Diffusion Approach," Management Science (36:2), 1990, pp. 123-139.

Davenport, T. H. "Putting the Enterprise into the Enterprise System," Harvard Business Review, July-August 1998.

DeSanctis, G., and Poole, M. S. "Capturing the Complexity in Advanced Technology Use: Adaptive Structuration Theory," Organization Science (5:2), 1994, pp. 121-147.

DiMaggio, P. J., and Powell, W. W. "The Iron Cage Revisited: Institutional Isomorphism and Collective Rationality in Organizational Fields," American Sociological Review (48), 1983, pp. 147-160.

Fichman, R. G., "The Diffusion and Assimilation of Information Technology Innovations," in Zmud, R. (Ed.), Framing the Domains of IT Management Research, Pinnaflex Educational Resources, Cincinnati, OH, 2000.

Fichman, R. G., and Kemerer, C. F. "The Illusory Diffusion of Innovation: An Examination of Assimilation Gaps," Information Systems Research (10:3), 1999, pp. 255-275. 
Firth, D. R. "The Organizing Vision for Customer Relationship Management," in D. Strong and D. Straub (eds.), Proceedings of the $7^{\text {th }}$ Americas Conference on Information Systems, Boston, 2001, pp. 834-840.

Gallivan, M. "Organizational Adoption and Assimilation of Complex Technological Innovations: Development and Application of a New Framework," Data Base (32:3), 2001, pp. 51-85.

Hirt, S. G., and Swanson, E. B. "Emergent Maintenance of ERP: New Roles and Relationships," Journal of Software Maintenance and Evolution (13), 2001, pp. 373-397.

Keller, E. "Lessons Learned," Manufacturing Systems, November 1999, pp. 44 ff.

Klaus, H., Rosemann, M., and Gable, G. "What is ERP?", Information Systems Frontiers (2:2), 2000, pp. 141-162.

Kling, R., and Iacono, S. "The Control of Information System Developments After Implementation," Communications of the ACM(27), 1984, pp. 1218-1226.

Lieber, R. B. "Here Comes SAP," Fortune, October 2, 1995.

Markus, M. L., and Tannis, C. "The Enterprise Systems Experience-From Adoption to Success," in R. Zmud (ed.), Framing the Domains of IT Management Research. Cincinnati, OH: Pinnaflex Educational Resources, 2000, pp. 173-207.

Nelson, S. "The Implications of the 2001 CRM Hype Cycle," Decision Framework DF-13-0755, Gartner Group, April 3, 2001.

Orlikowski, W.J "Using Technology and Constituting Structures: A Practice Lens for Studying Technology in Organizations," Organization Science (11:4), 2000, pp. 404-428.

Orlikowski, W. J., and Barley, S. "Technology and Institutions: What Can Research on Information Technology and Research on Organizations Learn from Each Other?", MIS Quarterly (25:2), 2001, pp. 145-165.

Pinch, T. J., and Bijker, W. E. "The Social Construction of Facts and Artefacts: Or How the Sociology of Science and the Sociology of Technology Might Benefit from Each Other," Social Studies of Science (14), 1984, pp. 399-441.

Pozzebon, M. "Demystifying the Rhetorical Closure of ERP Packages," in V. Storey, S. Sarker, and J. I. DeGross (eds.), Proceedings of the $22^{\text {nd }}$ International Conference on Information Systems, New Orleans, 2001, pp. 329-337.

Ramiller, N. C. "The 'Textual Attitude' and New Technology," Information and Organization (11), 2001, pp. 129-156.

Ramiller, N. C., and Swanson, E. B. "Organizing Visions for IT and the IS Executive Response," unpublished working paper, revised June 2002, available from the authors.

Robey, D., Boudreau, M., and Rose, G. M. "Information Technology and Organizational Learning: A Review and Assessment of the Literature," Accounting, Management and Information Technologies (10:2), 2000, pp. 125-155.

Rogers, E. M. Diffusion of Innovations ( $4^{\text {th }}$ ed.), New York: Free Press, 1995.

Ross, J. W. "The ERP Revolution: Surviving Versus Thriving," MIT Sloan School of Management Working Paper, 1998.

Saga, V. L., and Zmud, R. W. "The Nature and Determinants of IT Acceptance, Routinization, and Diffusion," in L. Levine (ed.), Diffusion, Transfer and Implementation of Information Technology. Amsterdam: North-Holland, 1994, pp. 67-86.

Scott, W. R. Institutions and Organizations. Thousand Oaks, CA: Sage Publications, 1995.

Simon, H. A, "Designing Organizations for an Information-Rich World," in M. Greenberger (ed.), Computers, Communications, and the Public Interest. Baltimore: Johns Hopkins Press, 1971, pp. 38-52.

Smith, J. F. "Blue Skies, No Risks," Manufacturing Systems (17:4), 1999, pp. 81-86.

Swanson, E. B. Information System Implementation, Homewood, IL: Irwin, 1988.

Swanson, E. B. "Innovating with Packaged Business Software in the 1990s," IS Working Paper 3-00, Anderson School, University of California, Los Angeles, September 7, 2000. 
Swanson, E. B., and Ramiller, N. C. "The Organizing Vision in Information Systems Innovation," Organization Science (8), 1997, pp. 458-474.

Wang, P. "What Drives the Waves in Information Technology: IT Discourse from the Organizing Vision Perspective," IS Working Paper 2-02, Anderson School, University of California, Los Angeles, February 22, 2002.

Weick, K. Sensemaking in Organizations, Thousand Oaks, CA: Sage Publications, 1995.

Willcocks, L. P., and Sykes, R. "The Role of the CIO and IT Function in ERP," Communications of the ACM (43:4), 2000, pp. 32-38.

Wolfe, R. A. "Organizational Innovation: Review, Critique, and Suggested Research Directions," Journal of Management Studies (31), 1994, pp. 405-431.

Wylie, L. "ERP: A Vision of the Next-Generation MRP II," Scenario S-300-339, Gartner Group, April 12, 1990.

Xenakis, J. "Taming SAP," CFO, March 1996, pp. 23-30.

\section{About the Author}

E. Burton Swanson is a professor Information Systems at the Anderson School, University of California, Los Angeles. His research focuses on information systems innovation, implementation, utilization, and maintenance. His academic career is complemented by his 10 years experience with IBM, primarily in computer application system development. He is the author of some 75 publications, and has served in an editorial capacity on several industry publications. He was founding editor-in-chief of the journal Information Systems Research from 1987-1992, a cofounder of the International Conference on Information Systems (ICIS) in 1980, and founding member of the Association for Information Systems (AIS) in 1994. Swanson is an active member of the Southern California chapter of the Society of Information Management (SIM), an association of leading IS executives and senior professionals. He also works with Information Systems Associates, a group of senior practitioners who support Anderson's Information Systems Research Program, and teaches regularly in Anderson's Executive Education Program, Managing the Information Systems Resource. 